\title{
TRAJETÓRIA DE VIDA DE MIGUEL DE OLIVEIRA COUTO (1865 - 1934), MÉDICO, EDUCADOR E POLÍTICO
}

\section{JOSÉ MARIO D'ALMEIDA}

http:/ /orcid.org/0000-0001-9016-3441

Universidade Federal Fluminense

CLAUDIA ALVES D́́ALMEIDA

http://orcid.org/0000-0001-7274-2757

Fundação Osvaldo Cruz

RESUMO

Com o presente trabalho apresentamos a trajetória acadêmica e profissional do médico Miguel de Oliveira Couto (1865-1934), voltada para três áreas: Clínica, Educação e Política. Foram abordados importantes pontos da carreira médica de Miguel Couto, como clínico em hospitais como a Santa Casa de Misericórdia e o Hospital São Sebastião, ambos na Cidade do Rio de Janeiro, como professor de Clínica Médica da Faculdade de Medicina do Rio de Janeiro. Foram abordadas as suas atividades políticas, como deputado constituinte de 1934, defensor ferrenho da Educação. Procuramos também discutir as suas ideias, muitas extremamente conflitantes, segregacionistas e racistas, muito embora, adotadas pela maioria dos intelectuais da época.

Palavras-chave: Miguel Couto. Constituinte de 1934. Pensamento médico.

\section{ABSTRACT LIFE TRAJECTORY OF MIGUEL DE OLIVEIRA COUTO} (1865 - 1934), DOCTOR, EDUCATOR AND POLITICIAN

With the present work we present the academic and professional trajectory of the doctor Miguel de Oliveira Couto (1865-1934), focused on three areas: Clinic, Education and Politics. Important points of Miguel Couto's medical career were discussed, as a clinician in hospitals such as Santa Casa de Misericórdia and Hospital São Sebastião, both in the city of Rio de Janeiro, as a professor of Clinical Medicine at the Faculty of Medicine of Rio de Janeiro. His political activities were discussed, as a 1934 constituent deputy, staunch advocate of Education. We also tried to discuss his ideas, many of which were extremely 
conflicting, segregationist and racist, although they were adopted by most intellectuals of the time.

Keywords: Miguel Couto. Constituent of 1934. Medical thought. COUTO (1865-1934), MÉDICO, EDUCADOR Y POLÍTICO

Con el presente trabajo presentamos la trayectoria académica y profesional del doctor Miguel de Oliveira Couto (1865-1934), centrada en tres áreas: Clínica, Educación y Política. Se discutieron puntos importantes en la carrera médica de Miguel Couto, como clínico en hospitales como Santa Casa de Misericórdia y Hospital São Sebastião, ambos en la ciudad de Río de Janeiro, como profesor de Medicina Clínica en la Facultad de Medicina de Río de Janeiro. Se discutieron sus actividades políticas, como diputado constituyente de 1934, firme defensor de la educación. También tratamos de discutir sus ideas, muchas de las cuales eran extremadamente conflictivas, segregacionistas y racistas, aunque fueron adoptadas por la mayoría de los intelectuales de la época.

Palabras clave: Miguel Couto. Constituyente de 1934. Pensamiento médico.

\section{Introdução}

A carreira do médico Miguel Couto, entre os anos de 1885 e 1934, esteve voltada para três áreas: a primeira delas foi a área médica, ligada à sua formação acadêmica, na qual foi considerado um dos mais brilhantes clínicos do Rio de Janeiro, no final do século XIX e início do século $X X$, clinicando em importantes hospitais; a segunda atividade do nosso personagem foi exercida na área de Educação, como professor da Faculdade Nacional de Medicina, atualmente Faculdade de Medicina da Universidade Federal do Rio de Janeiro (UFRJ). Convém ressaltar que o envolvimento com a atividade educacional esteve relacionado com a terceira frente de trabalho do médico doutor ${ }^{1}$ Miguel Couto, que foram as atividades políticas, como deputado da Constituinte em 1934,

1 Miguel Couto diplomou-se pela Academia Imperial de Medicina em 1883 sendo, portanto, médico, foi assistente da Cadeira de Clínica Médica até doutorar-se em 1885 , tornando-se, pois, doutor. com projetos voltados para a melhoria da educação do povo brasileiro. Participou de várias associações médicas e educacionais, como a Academia Nacional de Medicina (ANM) e a Academia Brasileira de Letras ( $A B L)$, instituições integradas por ilustres intelectuais. Inúmeros foram os motivos que nos levaram a estudar a trajetória acadêmica do Dr. Miguel Couto, dentre eles, nos chamou a atenção uma pergunta básica: Apesar de muitas homenagens, prêmios criados com o seu nome (Prêmio Miguel Couto) da ANM, por que as fontes de consulta são escassas? Em meio à literatura pesquisada, sobre o nosso personagem, observamos conflitos ideológicos, envolvendo assuntos polêmicos, tais como: eugenia, autoritarismo e racismo, embora que, contestados por Couto.

Também, chamou-nos a atenção certos aspectos relativos à sua personalidade, até no discurso de recepção, escrito por Mario de 
Alencar (1872-1925), filho de Jose de Alencar, na $A B L$, encontramos também indicativos sobre o quão misterioso poderia ser Miguel Couto, nas palavras do autor:

O lampião de querosene fez-se lâmpada elétrica, o sobrado da Prainha dilatou-se no palacete de Marquês de Abrantes, a clientela da Saúde universalizou-se em clientela de toda a Capital e do Brasil [...] Não consentis que o descanso vos feche as pálpebras antes de concluída a tarefa cotidiana [...] E assim realizais a tarefa formidável de acompanhar pari passu as múltiplas, diárias, infatigáveis pesquisas e descobertas das ciências médicas que em anos edificam bibliotecas e inundam revistas de todas as línguas, num sem-conto que parece emular a ação das moléstias e da morte. [...]A vossa atitude é a da curiosidade tímida, que não abona para o comum dos homens a posse da sabedoria; a vossa palavra, quando não exercita o dever do professor, sussurra e pergunta, que não recita nem afirma; e o vosso semblante sorri em plácido alheamento de vós mesmo. Esse é o vosso enigma, e eu quis entendê-lo, e penso explicá-lo - pedindo-vos que me releveis à conta de mau psicológico o meu engano ou a minha indiscrição. [...]Contentastes-vos com as vossas lições de professor, que dão a medida do que seria a vossa obra, realizada num pensamento de glória. Sábio, sem o aspecto de sábio; autor em virtualidade, sem a ambição de o ser em grandes livros que seriam razão de orgulho para a medicina brasileira; erudito, sem intolerância; penso ter achado a solução do vosso enigma: vós sois um cético. (ABL, 2019)

Assim sendo, com o presente trabalho, objetivamos discutir aspectos ligados à trajetória de vida e produção acadêmica do médico, educador e político Miguel de Oliveira Couto

\section{Dados biográficos do Dr. Miguel} Couto

Miguel de Oliveira Couto nasceu em $1^{\circ}$ de maio de 1865 no Rio de Janeiro, no bairro da Saúde, filho do português Francisco de Oliveira Couto e da brasileira Maria Rosa do Espírito Santo; era o filho mais novo de quatro irmãos. Ficou órfão de pai aos cinco anos, recebendo da mãe os primeiros ensinamentos de leitura e escrita. Sobre a sua mãe, falava Miguel Couto:

A formação do meu caráter a elas devo: a primeira - minha mãe, que costurava dia e noite para extrair do anonimato da nossa extrema pobreza, um doutor. Enquanto viveu, privei-me de construir família, para não dividir a dedicação que the devia; a outra aquela que transformou em realidade a minha visão Canaã e é há 20 anos a fonte e a inspiração de minha vida. (NAVARRO, 1950, p. 8)

Miguel Couto se referindo aos psicólogos, dizia que com essas suas declarações, certamente encontrariam explicações para o seu comportamento modesto (ACAMERJ, 2019). Morando em Niterói no Rio de Janeiro, estudou no Colégio Briggs onde cursou Humanidades. Nessa escola conheceu Alberto Torres, advogado, político e jornalista, deputado da Assembleia Constituinte do Estado do Rio de Janeiro (1892), deputado federal, ministro da Justiça e Negócios Interiores e ministro do Supremo Tribunal Federal (STF). Alberto Torres foi abolicionista e republicano, suas principais obras, segundo Alves (2016) foram - A organização nacional e $O$ problema nacional - que nasceram de artigos publicados no Diário de Notícias e no Jornal do Comércio. Nesses dois livros, Torres defende suas ideias nacionalistas além da defesa da miscigenação, posição encontrada também em seu último livro, As fontes da vida no Brasil, de 1915. Dessa amizade, surgem as discussões a respeito da "República, progresso e educação" (ALVES,2016). Convém destacar que muitas dessas ideias de Alberto Torres não foram, no futuro, compartilhadas por Miguel Couto, como veremos no decorrer do texto. Miguel Couto aos 15 anos começou a cursar a Faculdade de Medicina do Rio de Janeiro, além de trabalhar na farmácia do irmão mais velho. Era casado com Maria Barroso Jales Couto e pai de Miguel Couto Filho (1900-1969), que era 
médico, também envolvido com política, ministro da Saúde (1953-1954), foi governador do estado do Rio de Janeiro (1955-1958) e senador (1959-1967) (ALVES, 2016).

Miguel Couto faleceu no Rio de Janeiro em 6 de junho de 1934, ainda como deputado constituinte, em função de um ataque súbito de angina pectoris, após ter saído da missa de sétimo dia da escritora Júlia Lopes de Almeida. De acordo com Alves (2016, p. 42), Couto antes do término da missa dirigiu-se à Drogaria Granado, em busca do médico Ramos, antigo interno seu, para os primeiros socorros. Já no palacete da Praia de Botafogo, o ilustre médico, ainda lúcido, esclareceu a médicos conhecidos, que o atendiam, inclusive o seu filho, a gravidade do caso.

Figura 1 - Casa onde morou o Dr. Miguel Couto, na praia de Botafogo, Rio de Janeiro (RJ)

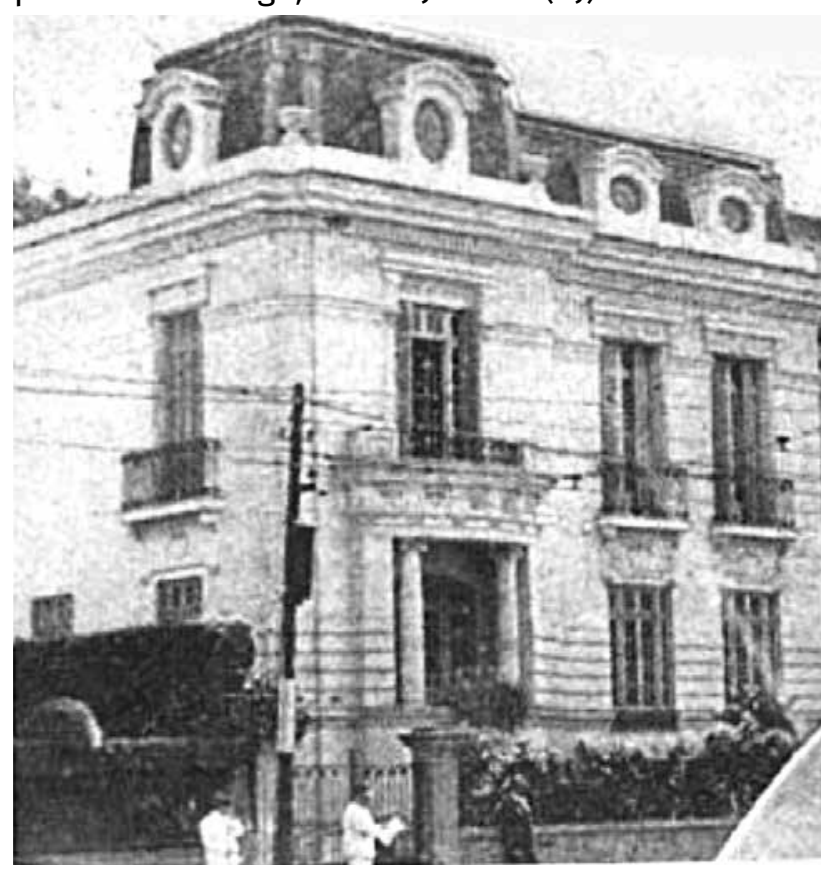

Fonte: https://rioquemoranomar.blogspot.com/.

\section{Dr. Miguel Couto, clínico e professor da Faculdade de Medicina (1885 - 1930)}

Dr. Miguel Couto foi considerado, por seus pares, um dos mais brilhantes clínicos do Rio de
Janeiro, tenaz defensor da medicina preventiva, junto à população (COUTO, 1927). É importante destacar, também, o lado humano de Couto, ressaltado em depoimentos registrados por muitos amigos e admiradores:

Segundo relatos de amigos próximos, como Alberto Torres, muitas vezes grandes nomes da política brasileira, esperavam em seu consultório, na sala de espera ao lado de moradores de bairros pobres da cidade. 0 compositor Noel Rosa, justifica a sua saída da Faculdade de Medicina para o médico Lauro de Abreu Coutinho dizendo - 'como médico eu jamais serei um Miguel Couto. Quem sabe não posso ser um Miguel Couto do samba' (NAVARRO, 1950, s/p).

Miguel Couto ingressou na Faculdade de Medicina da Academia Imperial de Medicina em 1880, com 15 anos, diplomando-se em 1885, com apenas 20 anos. Como acadêmico, foi interno, em seus dois últimos anos, na Santa Casa de Misericórdia, sob a orientação do Prof. José Pereira do Rêgo, Barão do Lavradio (1816-1892), médico muito prestigiado, não só nesse respeitado hospital, como também em todo o Império brasileiro e no Reino português, lá recebeu alguns títulos, como Comendador da Real Ordem Militar Portuguesa da Nossa Senhora da Conceição de Vila Viçosa, dentre outros. Convém destacar a importância desse primeiro contato do jovem Miguel Couto com tão importante orientador, para a sua promissora carreira (COC, 2019). Depois, foi assistente interno, por concurso, de um renomado médico o Prof. João Vicente Torres Homem (1837-1887) (ANM, 2019).

Formou-se pela Faculdade de Medicina em 1885, com a tese Da Etiologia Parasitária em relação às Doenças Infecciosas. Convém destacar que a Faculdade de Medicina cursada por Miguel Couto, atualmente Faculdade de Medicina da UFRJ, teve várias denominações: Escola Anatômica, Cirúrgica e Médica do Rio de Janeiro (1808); Academia Médico-Cirúrgica do Rio de 
Janeiro (1813); Faculdade de Medicina do Rio de Janeiro (1832); Faculdade de Medicina e Farmácia do Rio de Janeiro (1891); Faculdade de Medicina do Rio de Janeiro (1901); Faculdade de Medicina da Universidade do Rio de Janeiro (1920); Faculdade Nacional de Medicina da Universidade do Brasil (1937) e Faculdade de Medicina da UFRJ (1965) (COC, 2019).

Após a formatura, Couto inicialmente clinicou em São Paulo, por curto período, retornando para a Capital Federal em 1886, no Distrito Federal, novamente procurou a Santa Casa de Misericórdia, onde foi assistente do Prof. Antônio José da Silva Rabello. No Hospital São Sebastião, também no Rio de Janeiro, Miguel Couto realizou um brilhante trabalho, com o pesquisador Francisco Fajardo (1864-1906), sobre a Febre Amarela, que atingia a cidade:

Em 22 de julho, os delegados do Rio de Janeiro subiram à tribuna da Academia Nacional de Medicina para relatar a descoberta a uma platéia 'excepcionalmente' numerosa, formada por médicos, estudantes e espectadores de 'diversas classes sociais'. João Batista de Lacerda falou do orgulho que sentiam os uruguaios pelo Instituto de Higiene, 'sem igual na América do Sul', e descreveu as investigações que culminaram no isolamento de um bacilo extremamente virulento, que reproduzia os sintomas característicos da febre amarela quando inoculado em animais, realizando-se as experiências em uma ordem zoológica de crescente complexidade: roedores, ruminantes, símios, por último o homem. Relatou, por fim, as contraprovas que obtivera no laboratório da Diretoria Geral de Saúde Pública, com ajuda do dr. Emilio Gomes e a assistência de Chapot Prévost, Affonso Ramos, Zacharias Franco e Antonio Pimentel. Naquela mesma sessão da Academia e, dias depois, na Sociedade de Medicina e Cirurgia, Francisco Fajardo apresentou os resultados igualmente positivos das inoculações que efetuara com Miguel Couto no Laboratório Militar de Bacteriologia. (O BRAZIL-MEDICO, 1897, s/p)

Em 1891, inicia a sua vida de professor universitário, sucedendo na Faculdade de Medici- na, sem defender tese, o Catedrático de Clínica Propedêutica, o Prof. Francisco de Castro (18571901), conhecido no meio médico como "divino mestre", que havia falecido (CPDOC, 2019). Contudo, quando foi aberto concurso para a Cátedra de Clínica Médica, também ocupada por Francisco de Castro, Miguel Couto viveu uma terrivel fase de dúvidas sobre se faria a inscrição. Um dos concorrentes, Pedro de Almeida Magalhães (1864-1905), admirado pelo falecido catedrático e contando, por isso, com a admiração da Congregação da Faculdade, indiretamente afastava os possiveis competidores. Mesmo com a insistência de amigos e colegas mais próximos, Couto vacilou até os instantes finais da inscrição. Foi o médico Antônio Augusto de Azevedo Sodré (1864-1929), seu grande amigo, que acabou convencendo Miguel Couto a se inscrever no concurso, de forma impositiva, ordenando: “- inscreva-se!" (NAVARRO, 1950, p. 31-32).

Segundo Navarro (1950), nessa época, os candidatos a uma cátedra, arguiam-se mutuamente, frente à Congregação. Lá estavam, frente a frente Almeida Magalhães e Miguel Couto, candidatos com personalidades bem díspares, Magalhães exaltava-se, esmurrava a mesa, gritava, enquanto, Couto sem perder a compostura, respondia calmamente, com a sua característica simplicidade. Assim sendo, foi aprovado para a tão almejada Cátedra, iniciando sua carreira de professor universitário, exercida ao longo de 30 anos (ACAMERJ, 2019).

A obra bibliográfica médica de Miguel Couto esteve muito voltada aos relatos e análises de casos clínicos, muitos deles publicados nos seus dois volumes de Lições de Clínica Médica, o que faz até parecer, de forma equivocada, que a produção de Couto foi escassa (COUTO, 1916, 1923). É interessante ressaltar que nesses dois volumes de Lições de Clínica Médica, Couto relata os casos clínicos como se estivesse ministrando aulas para os seus alunos: 


\section{Prognostico das hemorragias nas afecções do estomago e do duodeno}

Meus Senhores

Continuamos hoje a conversar sobre a doença deste homem que foi o objeto da lição passada, e sobre o qual acordamos o diagnóstico de ulcus duodeni. Ouvistes-lo contar que ha mêses, sofrendo apenas de alguns symptomas dyspepticos e 'a que não ligara', sobretudo azia e adustão no estomago pela madrugada, foi um dia acometido de vômitos sanguíneos ao mesmo tempo que expellia do intestino enorme quantidade de sangue, a ponto de cahir vertiginoso [...] (COUTO, 1923, p. 15, grifos do autor)

Miguel Couto priorizou publicar os casos clínicos, que poderiam ser convertidos em artigos, como capítulos dos livros Lições de Clínica Médica, deixando claro a sua forte inclinação para o magistério, em detrimento da produção acadêmica, tão valorizada nos dias atuais. 0 volume 1 foi estruturado com 16 relatos de casos clínicos e cinco notas; enquanto o volume 2 dessa magistral obra, foi dividido em sete lições sobre análises de casos clínicos, 12 notas de ambulatório e 19 estudos de casos clínicos. Ressalta-se que Couto também participou, como colaborador de muitos trabaIhos efetuados na Faculdade de Medicina e na Santa Casa de Misericórdia, onde foi Chefe da 18a Enfermaria, responsável pela instalação do primeiro aparelho de Raio X no Brasil (NAVARRO, 1950). Também teve uma atuação marcante no Hospital São Sebastião, na Ponta do Caju, Rio de Janeiro, onde eram priorizados os casos de doenças infectocontagiosas, chamando-se a atenção, nessa época, para a febre amarela, doença que atingia não só a capital federal, como também, outros estados da federação. Juntamente com Azevedo Sodré, Miguel Couto publicou o livro Tratado sobre a Febre Amarela, obra com inúmeros ensinamentos e observações pessoais, que serviu de guia para muitos clínicos.
Foi membro de muitas associações e academias médicas, não só no Brasil, como também em outros países. Dentre elas podemos destacar: Sociedade de Medicina e Cirurgia do Rio de Janeiro e da Paraíba; membro e vice-presidente da Sociedade Médica dos Hospitais do Rio de Janeiro; membro do Conselho Técnico e Administrativo da Faculdade de Medicina da Universidade do Rio de Janeiro; membro do Conselho Superior de Ensino e da Sociedade de Medicina de São Paulo. Foi sócio -benfeitor da Policlínica Geral do Rio de Janeiro (ANM, 2019).

No exterior, participou de algumas Entidades Científicas, como também, foi por elas homenageado, conforme registros da ANM:

Atuou como Membro Correspondente da 'Societé de Pathologie Exotique' de Paris, da Academia de Medicina de Havana, da Academia de Medicina da Colômbia, da Sociedade Médico-cirúrgica do Equador, da Sociedade de Ciências Médicas de Lisboa, da Sociedade Médica dos Hospitais de Paris, Membro Honorário da Sociedade de Medicina e Cirurgia de Niterói, da Academia Nacional de Medicina da França, da Academia de Medicina de Buenos Aires, da Academia de Medicina de Berlim, da Real Academia Médica de Roma, da Associação Médica Argentina e do Instituto Brasileiro de Estomatologia. Fundou e integrou a Sociedade de Neurologia, Psiquiatria e Medicina Legal. É o Patrono da Cadeira 6 da Academia de Medicina do Estado do Rio de Janeiro e da Cadeira 39 da Academia Brasileira de Medicina Militar. Além disso, destacou-se como Professor 'Honoris Causa' da Universidade de Buenos Aires e da Universidade de Lima (Peru) e recebeu a Medalha da Instrução Pública da Venezuela e da Coroa da Bélgica. (ANM, 2019, $s / p)$

Na ANM, Miguel Couto foi eleito membro titular da Academia com a Memória intitulada O Pneumogástrico na Influenza, empossado no dia 1o de abril de 1897, na Cadeira 9, ocupando em diferentes diretorias vários cargos, tornando-se presidente de 1913 a 1915. Após essa 
gestão, Couto foi reeleito seguidamente, até a sua morte em 1934. Foi aclamado Emérito em 1927 e presidente perpétuo em 1929. Também foi membro da Academia de Medicina do Rio de Janeiro, ocupando a Cadeira 6 (ACAMERJ, 2019). O nosso personagem, em 9 de dezembro de 1916, foi eleito membro da $A B L$, ocupando a cadeira 40, sucedendo, nada menos, que, o advogado, contista e romancista Afonso Arinos (1868-1916) (ABL, 2019).

Conforme já relatado, muitos dos trabalhos de Miguel Couto não foram publicados como artigos em periódicos especializados, mas como capítulos de seus livros de clínica médica, contudo a literatura médica destaca a importância das seguintes obras: Desordens Funcionais do Pneumogástrico na Influenza (1896), Dos Espasmos nas Afecções dos Centros Nervosos (1898), Febre Amarela (1901), Meralgia Parestésica na Colite Mucomembranosa (1913), Da Poliesteatose Visceral Curável (1914), Líquido Cefalorraquidiano na Febre Amarela (1916), Lições de Clínica Médica (v. 1, 1916 - v. 2, 1923), As alocuções do Presidente da Academia de Medicina (1923), Medicina e Cultura (1932) (COC, 2019).

Miguel Couto recebeu homenagens e citações de importantes letrados, dentre elas, destacamos as seguintes:

1. Homenagem feita pelo Dr. Carlos Chagas (1879-1934) na sessão de 14 de junho de 1934. "Carlos Chagas exalta as virtudes profissionais e pessoais de Miguel Couto, destacando os laços afetivos que o uniam ao amigo e mestre. Ressalta sua importância como um dos mais notáveis professores de Clínica Médica da época" (ANM, 2019, s/p).

2. Carta do imortal Machado de Assis (18391908) para Mario de Alencar, sobre o seu médico assistente e colega da ABL:

De mim vou bem, apenas com os achaques da velhice, mas suportando sem novidade o pecado original, deixe-me chamar-lhe assim. Creio que o Miguel Couto me trouxe a graça. (RIBAS, 2008, p. 60)

3. Homenagem pelos 25 anos de magistério do Prof. Miguel Couto na Faculdade de Medicina, assinaram esse documento 59 médicos. Destacamos, basicamente, pela ligação com a pesquisa acadêmica os seguintes médicos: Aloysio de Castro (1881-1959), Álvaro Osório de Almeida (1882-1952), Antônio de Barros Terra (1879-1961), José Gomes de Faria (1887-1962), Candido de Melo Leitão (1886-1948), Miguel Osório de Almeida (1890-1952), Júlio Muniz (1898-1975), dentre outros renomados médicos (COUTO, 1923).

3. Sobre o Dr. Miguel Couto, o imortal Alceu Amoroso Lima, assim relata: "Dava à sua tarefa, à sua profissão, à sua insaciável curiosidade científica e social, essa imensa capacidade de dedicação, que o faria, por toda sua vida, conjugar o verbo servir, em todos os tempos" (ABL, 2019, s/p)

5. Miguel Osório de Almeida (1890-1953), pesquisador fisiologista do Instituto de Manguinhos (Instituto Oswaldo Cruz), ex-discípulo, assim se refere ao Dr. Miguel Couto, em discurso na ABL:

A ciência poderá um dia vos reclamar tudo o que the havieis prometido. Mas o que vale a ciência, falaz, precária e balbuciante, diante dessa verdade eterna, insofismável, indestrutivel: a caridade? E vós reunistes as duas. $\mathrm{Na}$ vida de um sábio completo, só é perfeita a atitude da inclinação para o estudo quando termina na prosternação para a prece. Foi sempre essa a missão de Miguel Couto. E sua vida um admirável equilíbrio entre a bondade e o conhecimento (ACAMERJ, 2019, s/p)

O Dr. Miguel Couto teve destacada participação, como médico, em defesa de teorias eugê- 
nicas. Contudo, convém ressaltar que a Eugenia, como outras teorias polêmicas, eram defendidas por muitos intelectuais, médicos, advogados, engenheiros, dentre outros letrados.

\section{Miguel Couto na Política e na Educação}

O Dr. Miguel Couto foi um dos mais respeitados e prestigiados clínicos no Rio de Janeiro e no Brasil, como também em outros países, no final do século XIX e nas três primeiras décadas do século XX, tendo sido também elogiado pela comunidade acadêmica como um exímio professor de Clínica Médica da Faculdade de Medicina do Rio de Janeiro. Enfim, escrever sobre Miguel Couto, médico e professor, não foi uma tarefa complicada, mesmo incorrendo na tão criticada "biografia heroica", ressaltandose que a vida acadêmica de Miguel Couto foi muito interessante, reverenciada por todos. Contudo, quando se discute as ideologias adotadas pelo nosso personagem, criam-se polêmicas e as controvérsias se avolumam, portanto, iniciaremos esse tópico discutindo as suas ideias.

Engel (2012) ressalta muito bem as contradições ideológicas de Couto, em especial, os preconceitos ligados a estrangeiros, excluindo os brancos europeus:

A miscigenação, reconhecida como característica irrefutável da sociedade brasileira, assume aqui claramente o sentido de branqueamento, cujo atributo purificador representaria um -grande serviço à humanidade. Longe de promover a integração entre as diferenças, a mistura do -nosso sangue - branco e brasileiro - promoveria a depuração -dessa raça, negra e estrangeira. Reconhecendo as controvérsias em torno da definição do termo raça - que ainda não teria sido fixado pela própria ciência, o deputado ressaltava a existência de diferenças entre -pretos, amarelos e brancos: -classifiquem-nos como quiserem, mas são diferentes. Pelo que vimos em relação às concepções de- fendidas por Miguel Couto, podemos concluir que o sentido das diferenças entre as raças, seja qual for o seu significado, pressupõe a sua hierarquização em -inferiores e -superiores. (ENGEL, 2012, p. 22)

O nosso personagem participou da criação de várias associações, denominadas "ligas" e academias, tendo sido membro ativo de muitas delas. Dentre essas ligas, convém destacar a Liga de Defesa Nacional (LDN), fundada na Cidade do Rio de Janeiro em 7 de setembro de 1916, por juristas, médicos, escritores, militares de alta patente, empresários, digamos, uma significativa parcela da intelectualidade brasileira, dentre eles, centro do nosso estudo, o Dr. Miguel Couto. A LDN defendia, principalmente, o apoio aos aliados da Primeira Grande Guerra (1914-1918) e a ideia defendida ferrenhamente pelo Poeta Olavo Bilac de "cidadão soldado" (ENGEL, 2012). Contra esses princípios da LDN, voltaram-se os partidários do Anarquismo e alguns escritores, como Lima Barreto (18811922). Em sua obra Triste Fim de Policarpo Quaresma, Barreto (2011) mostra a decepção do personagem Policarpo Quaresma, não só com a guerra, como também, com os ensinamentos ministrados pelos militares, defendidos pelo programa de ação da LDN:

Fiquei com um horror à guerra que ninguém pode avaliar... Houve momento em que abandonamos as armas e fogo: batíamo-nos à baioneta, a coronhadas, a machado, facão. Filha: um combate de trogloditas, uma coisa pré-histórica... Eu não vi homens de hoje; vi homens de Cro-Magnon, do Neanderthal armados com machados de sílex, sem piedade, sem amor, sem sonhos generosos, a matar, sempre a matar...Eu matei, minha irmã; eu matei! E não contente de matar ainda descarreguei um tiro quando o inimigo arquejava a meus pés [...]. (BARRETO, 2011, p. 35)

Dentre outros letrados da época, críticos dos princípios da LDN, destaca-se Alberto Torres (1865-1917) que, segundo Fonseca (2004), 
foi um dos primeiros intelectuais a fazer inferências sobre o significado de "raça", no Brasil, elogiando a "mestiçagem", tão criticada por certas ligas, algumas, oriundas da LDN. Outro personagem, de grande importância como crítico da segregação racial, foi o sociólogo Gilberto Freyre (1900-1987), que exaltou a identidade brasileira pela fusão das três raças, formadoras da nossa nacionalidade: branco, índio e negro (FREYRE, 2006).

O programa de ação da LDN visava promover, acima de tudo, o nacionalismo e o patriotismo entre os brasileiros:

A criação da Liga da Defesa Nacional foi um desdobramento da campanha, promovida entre 1915 e 1916 pelo poeta Olavo Bilac em prol da implantação do serviço militar obrigatório no Brasil. Essa campanha, lançada pela primeira vez em 1907, no governo Afonso Pena (1906-1909), quando o general Hermes da Fonseca ocupava a pasta da Guerra, recebeu então o apoio do general Caetano de Faria, ministro da Guerra do presidente Venceslau Brás (19141918). O serviço militar era concebido pelos seus defensores como um instrumento capaz de apagar as fronteiras entre civis e militares, através da disseminação da 'consciência civil' nos quartéis. O 'cidadão-soldado', fruto desse processo de amálgama que desembocaria na identificação Exército-nação, constituiria uma 'força nacional real', de grande importância para a solução dos problemas do país. A defesa do serviço militar obrigatório instituído em outubro de 1916 inseria-se no quadro maior de uma campanha nacionalista em grande escala, centrada no tema do patriotismo e do culto às tradições brasileiras. Essa cruzada de civismo produziu, além da LDN, a Liga Nacionalista de São Paulo, fundada em dezembro de 1916 por estudantes da Faculdade de Direito. (LIGA DA DEFESA NACIONAL, Estatutos, 2016, p. 57)

Esses programas nacionalistas, autoritários e segregacionistas, de muitas das ligas, destacando-se a LDN, persistiram durante muitos anos, enfraquecendo-se com a Segunda Grande Guerra (1939-1945) e com a ascensão dos regimes totalitários, em especial o Nazismo.

Embasadas nos princípios da LDN, surgiram outras associações, como a Liga Brasileira contra o Analfabetismo (7/9/1915); Liga Pró Saneamento do Brasil (11/2/1918); dentre outras, contudo, destacando-se a Sociedade de Eugenia de São Paulo em 1917.

Figura 2 - Criança premiada como Bebê Eugênico: Imagem apresentada no trabalho "A influência da educação sanitária na redução da mortalidade infantil" no Congresso de Eugenia de fevereiro de 1929, São Paulo

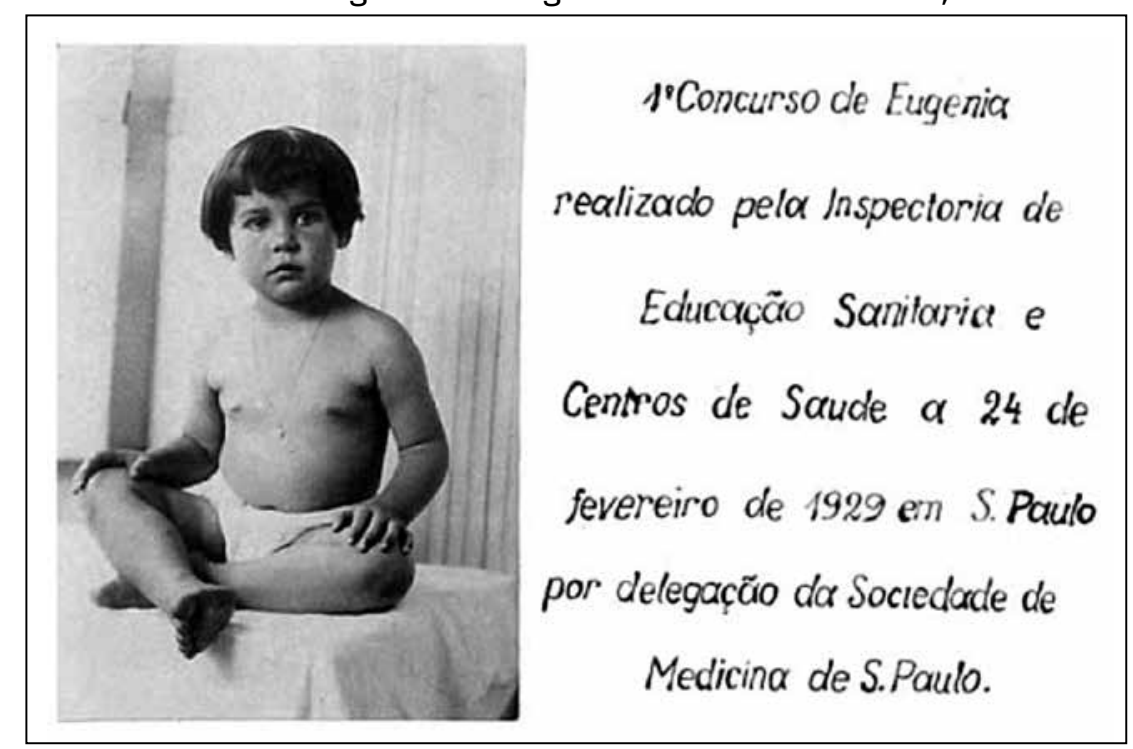

Fonte: Fotografia de Ademir F. de Carvalho. Acervo Arquivo de Antropologia Física. Museu Nacional/UFRJ. 
É interessante ressaltar que a sessão de instalação da LDN foi realizada na Sociedade Nacional de Agricultura, em 1916, demonstrando a concepção ruralista de nossos intelectuais, o que talvez permaneça até os dias de hoje. A filiação da intelectualidade da época a essas ligas, muitas delas, de princípios nacionalistas, autoritários e discriminativos, como a LDN, foi enorme. Para dar maior representatividade à LDN, foram convidados para a presidência e vice-presidência os doutores Carlos Chagas e Juliano Moreira, respectivamente e o discurso de abertura foi proferido pelo médico sanitarista Belisário Pena (ENGEL, 2012), cientistas de grande representatividade na ciência brasileira. Podemos ressaltar que o convite a Belisário Pena pode estar associado a uma expedição realizada pelo convidado e pelo médico, sanitarista e político Arthur Neiva ao interior do Brasil, onde esses renomados cientistas retrataram a triste situação do sertanejo (NEIVA; PENNA, 1912). Segundo Bomeny (1993), Belisario Penna não só destacava o "branqueamento da raça", como também, o saneamento, visando a melhoria do vigor físico, aprimoramento da raça e, digamos até de forma "fantasiosa", produção de alegria, da riqueza e do progresso. Outra associação que marcou o início do século XX, uma das mais significativas, foi, sem dúvidas, a Sociedade de Eugenia de São Paulo, fundada em 1917 pelo médico e farmacêutico Renato Kehl (1889-1974). Segundo Stepan (2004), duas correntes eugenistas prevaleceram no Brasil: uma delas, inspirada nos princípios lamarckistas, ${ }^{2}$ liderada por Renato Kehl; e a outra, baseada nas concepções men-

2 O Lamarckismo foi uma teoria proposta e criada no século XIX por Jean-Baptiste Lamarck (1744-1829) para explicar a evolução das espécies. Lamarck acreditava que mudanças no ambiente causavam mudanças nos organismos que ali viviam, como também no seu comportamento. O Lamarckismo baseia-se em duas leis: Lei do uso e desuso e Lei da transmissão dos caracteres adquiridos; foram descritas na obra Philosophie Zoologique. (WIKIPEDIA, 2020). delianas, ${ }^{3}$ tendo como principal seguidor o engenheiro agrônomo Otávio Domingues (18971972). Mesmo com as duas correntes adotando a mesma definição de Eugenia, apresentavam visões diferentes sobre miscigenação, isto é, a mistura de raças, sendo conveniente ressaltar que a corrente lamarckista considerava a miscigenação uma forma de degeneração da espécie humana, enquanto a mendeliana pregava o embranquecimento (STEPAN, 2004). As polêmicas foram muitas, o médico, zoólogo, antropólogo João Batista de Lacerda, em um Congresso Universal das Raças, em Londres, em 1911, representou o Brasil, apresentando uma tese sobre o "Embranquecimento da Raça Negra", em que com esses ideais eugenistas postulavam que após alguns anos os negros seriam poucos (SCHWARCZ, 2011). Outra liga, surgida em 1911, também inspirada nos princípios da LDN, foi a Liga Brasileira de Higiene Mental, com muitos médicos a ela associados. Na maioria dessas ligas, Couto estava presente como ativo participante.

Com o discurso higienista, buscava-se uma regeneração sanitária e estética da cidade, procurando combater tudo aquilo que fosse considerado ultrapassado para as sociedades civilizadas. Dessa maneira, principalmente se tratando do Rio de Janeiro, a cidade deveria ser uma vitrine para os países latinos e para isso deveria retirar, esconder, aqueles que "não se enquadravam nos padrões europeus nem pelo comportamento político, nem pela cultura, nem pela maneira de morar, nem pela cara" (CARVALHO, 1990, p. 162).

Para o personagem de nossa história, Dr. Miguel Couto, a saúde não era a única preocupação brasileira, para ele, o que mais preocupava era a ignorância da população. Enquanto para um outro ilustre personagem da

3 Conjunto de leis e princípios relacionados à transmissão hereditária, tendo como origem os trabalhos do Abade Gregor Mendel (1822-1884), publicados em 1866, contudo, redescobertos e reestudados em 1900. 
época, também eugenista, o escritor Coelho Neto, a preocupação maior era o analfabetismo, que grassava $80 \%$ da população brasileira (ENGEL, 2012). Nos parece que os conceitos de "ignorância" e "analfabetismo" têm muitos pontos em comum, ou pelo menos são convergentes. Contudo, Miguel Couto insistia enfaticamente no discurso da importância maior da ignorância:

A ignorância é uma calamidade pública como a guerra, a peste, os cataclismos, e não só uma calamidade, como a maior de todas, porque as outras devastam e passam, como tempestades seguidas de céu bonança; mas a ignorância é qual o câncer, que tem a volúpia da tortura no corroer célula a célula, fibra por fibra, inexoravelmente o organismo; dos cataclismos, das pestes e das guerras se erguem os povos para as bênçãos da paz e do trabalho: na ignorância se afundam cada vez mais para a subalternidade e a degenerescência. Imaginemos - quod Deos avertat - que somos surpreendidos um dia por uma irrupção inimiga. Que faremos? Do nada tudo até eliminá-la do solo sagrado. Por que, pois, a passividade ante as tremendas consequências da ignorância? Ou o Brasil a encara como uma calamidade nacional e the acode com o socorro imediato ou estará irremediavelmente batido na concorrência com as nações cultas. (ABL, 2019, s/p)

Miguel Couto, como médico, representando as classes cultas de uma elite privilegiada, chamava para si a construção de um país civilizado, o que significava demonstrar que toda essa doutrinação estava voltada para um povo, dócil, obediente, não contestador, seguindo os princípios da LDN (ROCHA, 1995).

Esse pensamento elitista, adotado por Miguel Couto estava enfronhado em toda classe médica da época, tal como, acreditamos que ocorra até os dias de hoje. Em sua obra Lima Barreto: Triste Visionário, Schwarcz (2017), em alusão ao avô do escritor Lima Barreto, referese aos médicos como uma espécie de "teocracia médica".
Foucault, com relação ao poder e os intelectuais, afirma:

Ora, o que os intelectuais descobriram recentemente é que as massas não necessitam deles para saber; elas sabem perfeitamente, claramente, muito melhor do que eles; e elas o dizem muito bem. Mas existe um sistema de poder que barra, proíbe, invalida esse discurso e esse saber. Poder que não se encontra somente nas instâncias superiores da censura, mas que penetra muito profundamente, muito sutilmente em toda a trama da sociedade. Os próprios intelectuais fazem parte deste sistema de poder, a idéia de que eles são agentes da 'consciência' e do discurso também faz parte desse sistema. 0 papel do intelectual não é mais o de se colocar 'um pouco na frente ou um pouco de lado' para dizer a muda verdade de todos; é antes o de lutar contra as formas de poder exatamente onde ele é, ao mesmo tempo, o objeto e o instrumento: na ordem do saber, da 'verdade', da 'consciência', do discurso. (FOUCAULT, 2008, p. 71)

Muitas das propostas do Dr. Miguel Couto, mesmo com objetivos nobres, parecem que traziam embutidas visões extremamente autoritárias, desconsiderando o direito das classes mais pobres, impondo o poder da intelectualidade, tão bem discutido por Michel Foucault (FOUCAULT, 2008, p. 71). Rocha (1995), em sua Dissertação apresenta interessantes textos de Couto, como aquele referente a "tutela higiênica através das escolas maternais":

Dos três aos sete anos, atutelagem do Estadovae se exercer tambem através da 'Escola Materna' ou 'Casa da Criança'ou 'Jardim da Infancia', denominações anodynas que se valem, quaisquer que sejam as divergencias dos processos, porque há em todos o mesmo obje(tivo: tendo em conta os phenomenos physiologicos, somáticos e psychicos, que se passam e se desenvolvem naquela edade da vida, seguí-los sem maltratá-los, tal qual como se fosse uma plantinha tambem em crescimento, que só pede que a preservem de contaminações parasitarias de deformações desgraciosas, da excessiva acção urente do sol ou humectante da chuva. É um laboratório de orthopedia moral, para ser 
confiada a uma hygienista, - como o devem ser todas as professoras, - versada na psychologia infantil e de grande intuição pedagógica. (COUTO, 1933, p. 49, apud ROCHA, 1995, p. 100)

Outra proposta de Couto, que nos parece muito polêmica, contudo, talvez até condizente com o contexto de época, isto é, o "poder da intelectualidade", foi a proposta das professoras primárias, como as "garças brancas", conforme o seguinte texto:

Mensageiras de cultura e de bondade, como bandos de garças brancas deixando cahir plumas brancas, lá vão as santas professoras brasileiras para o seu apostolado de fazer de cada criança um homem forte pelo caracter, útil pela inteligência, bom pelo contagio (COUTO, 1933, p. 41, apud ROCHA, 1995)

Nessa proposta, nos parece claro que Couto considerava que o trabalho das "garças brancas" era um apostolado, no qual as professoras eram obrigadas a renunciar a "vida terrena e aos prazeres da carne"

O envolvimento do Dr. Miguel Couto com a eugenia foi marcado por certas particularidades, como pode-se observar nas palavras de Takeuchi:

Nos debates empreendidos por Couto, Neiva e Xavier de Oliveira, os imigrantes japoneses e seus descendentes no Brasil foram qualificados como indivíduos feios, hipócritas, portadores do eterno sorriso, que obedeciam tão-somente às ordens de seus chefes. Estes, por sua vez, receberiam os comandos diretamente do governo japonês. Os homens do complô nipônico considerariam legítimos todos os meios para a destruição da nação brasileira, inclusive a espionagem. Eram, em suma, na expressão tomada de Miguel Couto, abutres e serpentes que se infiltravam, a fim de tomar todas as riquezas de nossa pátria. Xavier de Oliveira, em seus discursos, afirmara que os japoneses tinham tendência a desenvolver doenças mentais incuráveis. Já Artur Neiva considerava que os nipônicos, além de serem muito mais organizados do que os brasileiros, não eram sinônimo de estética, ao contrário dos desejados imigrantes ibéricos, capazes de depurar a raça brasileira. (TAKEU$\mathrm{CHI}, 2008$, p. 178)

Contudo, de acordo com Miki (2015), o nosso personagem, diferentemente de Arthur Neiva e Xavier da Silveira, não afirmou serem os japoneses inferiores, temia, sim, que os nipônicos "nas Américas almejassem fazer dos seus emigrantes pequenos embaixadores, legítimos representantes do Japão e da raça amarela no exterior" (p. 65).

Em um outro momento, em sessão Constituinte, Couto, contraditoriamente, atacou diferentes raças, asiáticos e negros:

É proibida a imigração africana ou de origem africana, e só consentida a asiática na proporção, de 5 por cento, anualmente, sobre a totalidade de imigrantes dessa procedência existentes no território nacional. (ANNAES DA ASSEMBLÉA NACIONAL CONSTITUINTE, 1934)

Outra questão que nos parece conflitante está relacionada com a destinação de impostos para a Educação, em que no parágrafo relativo às bebidas alcoólicas, Couto estabelece uma distinção social quanto ao consumo dessas bebidas. Mesmo considerando a sua ingestão, também nefasta aos ricos, é ainda mais enfático em relação aos pobres:

No bojo das preocupações eugênicas presentes no período, é interessante notar a relação estabelecida entre alcoolismo-degeneração da raça-pobreza comprehende-se, pois, que a venda de um agente desta natureza, inimigo inexorável da espécie, destruidor no homem de suas energias physicas e de suas faculdades superiores, dissolvente do lar e da prole, fosse cercado das derradeiras barreiras até as raias da proibição, já aconselhada pela Academia de Medicina; nem ao menos é o tóxico elegante só ao alcance das bolsas fortes dos ricos, ao contrário é o vício deselegante propiciado ao pobre pelo seu ínfimo preço. (COUTO, 1927, p. 132)

Outra passagem interessante, reportada por Miki (2015), que se encontra registrada nos Anais da Assembleia Constituinte de 1934, re- 
laciona-se a uma carta de Miguel Couto para Oliveira Vianna (1883-1951), na qual o nosso personagem demonstra de forma cabal, que a humanidade se divide entre raças distintas e bem diferentes:

O que devemos procurar aqui introduzir são raças que sejam ricas em eugenismo. Ora, de todas as raças humanas, são as indo-europeias as que acusam um coeficiente mais elevado de eugenismo. Logo, só estas nos servem - porque o progresso das sociedades e a sua riqueza e cultura são criação dos seus elementos eugênicos, cuja função na economia social é análoga à função do oxigênio, na economia animal. Bem sei que não há raças desprovidas de eugenismo: têm-no o mais rude negro da África, como o saxão mais puro. Há, porém, raças mais fecundas em elementos superiores e raças menos fecundas. [...]

Para nós, portanto, que, pelo fato mesmo de termos uma formação em que predominam dois sangues inferiores (o negro e o índio), somos um povo de eugenismo pouco elevado, o grande problema é a arianização intensiva da nossa composição étnica. Tudo quanto fizermos em sentido contrário à arianização é obra criminosa e impatriótica. (ANNAES DA ASSEMBLÉA NACIONAL CONSTITUINTE, 1934)

Contudo, mesmo assim, de acordo com a literatura pesquisada, o Dr. Miguel Couto, se preocupava muito com a possibilidade de ser classificado de racista. Concordamos com Miki (2015), quando afirma que Couto, apesar de ter negado o racismo, apologizou a existência de raças distintas, superiores e inferiores. Nos parece, analisando a literatura obtida, que não ficou clara a "defesa" do Dr. Miguel Couto, quando afirma que "a forma de pensar e os hábitos culturais seriam os fatores mais importantes para a classificação racial, mais do que os aspectos físicos" (MIKI, 2015, p. 67).

Como político, o Dr. Miguel Couto teve participação deveras importante, na promulgação da Constituição de 1934, como deputado constituinte, eleito pelo Partido Econômico. O pres- tígio do Dr. Miguel Couto, junto aos letrados, em especial aos médicos, era tamanho que a sua candidatura à Constituinte foi lançada, através de um Manifesto assinado por 204 intelectuais, de várias formações (ROCHA, 1995).

Rocha (1995) transcreve na íntegra o manifesto dos intelectuais, com os nomes dos respectivos manifestantes, aqui apresentamos, apenas, parte do manifesto:

É este o manifesto dos intellectuaes lançando a candidatura do consagrado homem de sciencia: 'Approximando-se a data da eleição para a Assemblea Constituinte, não podiam os intellectuaes brasileiros, aqui residentes, e que se interessam pelo engrandecimento do Brasil, deixar de compartilhar do enthusiasmo cívico, que deve reinar nesta hora histórica, da qual esta dependendo o futuro da pátria comum'. Assim não thes era razoável deixar passar no olvido occasião em que pudessem trazer a sua colaboração áquella Assembléa, apresentando o nome de um intellectual cujas virtudes cívicas são sobejamente conhecidas: Professor Miguel de Oliveira Couto. (ROCHA, 1995, anexo 1 - grifos do autor)

Miguel Couto como constituinte foi enfático na defesa da Educação, embora, muitos dos projetos apresentados já tinham sido discutidos na 5a Conferência da Associação Brasileira de Educação ( $A B E$ ), em 1927, na qual o nosso personagem defendia enfaticamente a obrigatoriedade, gratuidade e alocação de recursos para o ensino, especialmente o primário (COUTO, 1992).

Convém ressaltar que Couto atuou também como político e educador, durante a Revolução Constitucionalista de 1932, desempenhando papel de mediador entre o governo e os revoltosos (BOMENY, 1993).

Mantendo as suas ideias originais, expressadas na Conferência de Educação de 1927, na Constituinte de 1934, Miguel Couto também se empenhou na criação do Ministério da Educação, com dois departamentos, o da Higiene e 
o da Instrução Pública. Contudo, mesmo antes da Constituinte de 1934, o Presidente Getúlio Vargas havia criado o Ministério da Educação e Saúde Pública, em 14 de novembro de 1930 (Decreto no 19.560).

Convém ressaltar que o médico Miguel Couto, ao eleger-se deputado, pôs em prática tudo aquilo que pregava em reuniões e eventos. De acordo com Ferreira-de-Jesus (2008), Couto, em 30 de novembro de 1933, após fundamentar um memorável discurso sobre educação "Educação Problema Nacional” propôs uma importante emenda constitucional, que marcou definitivamente a sua participação na Constituinte de 1934:

Emendas:

Art. O ensino primário, compreendendo a instrução moral, intelectual, física, e quando possível a profissional, é obrigatório; obrigatório ao governo em fornecê-lo e às crianças em idade escolar em freqüentá-lo.

$\S$ 1o. À União compete particularmente fornecer o ensino primário no interior do país.

$\S 2$ 2. Os pais e irmãos mais velhos, sempre que Ihes for possivel, têm o dever de dar a educação aos seus filhos e irmãos mais moços.

$\S 3$ 3o. 0 ensino primário fornecido pelo governo é único e gratuito.

$\S$ 4ㅇ. Vinte por cento das receitas da União, dos Estados e dos Municípios serão compulsoriamente destinados à educação e à saúde do Povo.

$\S$ 5o. Todos os impostos federais aplicados à Educação e higiene serão pagos diretamente num tesouro especial - o Tesouro da Educação - e nos Estados à 'Delegacia Federal da Educação'. Estas repartições serão geridas pelo Ministério da Educação e Higiene.

§ 6o. Destinam-se exclusivamente à educação e saúde de [sic] povo: 0 imposto sobre a renda; 0 imposto sobre o álcool; O selo educação;

As multas por faltas, contravenções e outras. Os municípios - salvo o distrito Federal - enviarão $20 \%$ das suas receitas diretamente a um tesou- ro especial em cada Estado, sob pena de perda da sua autonomia.

$\S 70$. A cada Estado compete o ensino primário nas suas cidades, vilas, povoados, etc.

Sala das Sessões, 30 de Novembro de 1933. - Miguel Couto. (ANAIS, 1934, p. 121)

Miguel Couto, como deputado constituinte, defendeu enfaticamente a premissa de que a educação significava uma "alavanca para o desenvolvimento", se bem que, essa opinião já fora preconizada no Manifesto dos Pioneiros da Educação Nova (PINTO, 2002).

\section{Considerações finais}

Ao longo do texto, procuramos discorrer sobre a trajetória do médico Miguel de Oliveira Couto, abordando as suas muitas atividades, não só como clínico e professor de Clínica Médica da Faculdade de Medicina, na qual foi reverenciado por seus pares, como também, abordamos as suas atividades políticas, como deputado na Constituinte de 1934, defendendo enfaticamente a educação como "problema nacional". Contudo, procuramos também mostrar que o brilhante médico foi uma figura contraditória, polêmica no que se refere às suas ideologias, defendendo ideias, consideradas hoje, autoritárias e segregacionistas, embora que, adotadas pela grande maioria dos letrados da época. Com referência aos médicos, incluindo Miguel Couto, evidencia-se uma visão teocrática, muito bem abordada por Schwarcz (2011), quando se refere a "teocracia médica", na sua obra Lima Barreto: Triste Visionário (2011). Esse comportamento, ainda presente nos médicos da atualidade, não interfere no fazer médico de muitos profissionais da medicina. Discutimos a influência da LDN, não só sobre os intelectuais da época, como também, sobre a criação de outras ligas e associações, algumas delas, pregando ideias segregacionistas, como a Sociedade de Eugenia de São Paulo. 
Considerando, portanto, a trajetória polêmica de Miguel de Oliveira Couto, destacamos a sua brilhante atuação como médico, clínico geral em importantes hospitais, como a Santa Casa de Misericórdia e o Hospital São Sebastião, ambos na Cidade do Rio de Janeiro, sempre reverenciado por seus pares. Como também destacamos as suas atividades como professor de clínica médica, ministrando aulas práticas elogiadas por seus alunos, alguns deles, destacados médicos e cientistas. Enfatizamos que o professor Miguel Couto priorizava o magistério em detrimento da produção científica, tendo em vista, que muitos dos seus casos clínicos teriam dado excelentes artigos científicos, contudo o nosso personagem preferiu transformá-los em capítulos de seus livros. Por fim, ressaltamos as suas atividades políticas, defendendo enfaticamente a educação. Entretanto, assim como os "homens de ciência" de sua época, é importante ressaltar que foi um cidadão adepto a ideologias racistas e segregacionistas.

\section{Referências}

ABL - ACADEMIA BRASILEIRA DE LETRAS. Miguel Couto. Rio de Janeiro. 2020. Disponível em: http://www. academia.org.br/academicos/miguel-couto/textos -escolhidosdisponível Acesso em: 20 out. 2019.

ANM - ACADEMIA NACIONAL DE MEDICINA. Cadeira 09, Miguel Couto. Disponível em: http://www.anm. org.br/conteudo_view.asp?id=586\&descricao=Miguel+de+Oliveira+Couto+(Cadeira+No.+09). Acesso em: out. 2019.

ACAMERJ - ACADEMIA DE MEDICINA DO ESTADO DO RIO DE JANEIRO. Cadeira n. 6: Miguel Couto. Rio de Janeiro, 2019. Disponível em: http:www.acamerj.org. br/cadeira06.htm. Acesso em: nov. 2019.

ALVES, Vera. Miguel Couto, Cadeira 40 / Ocupante 3. São Paulo: Ed. Academia Brasileira de Letras, 2016, 64 p.

ANAIS DA ASSEMBLÉIA NACIONAL CONSTITUINTE de 1934. Brasília, Câmara dos Deputados, vol. I-XX 1935. Disponivel em: http://www.camara.gov.br. Acesso em: out. 2019.

BOMENY, Helena. Novos talentos, vícios antigos: Os renovadores e a política educacional. Estudos Históricos. Os anos 20, Rio de Janeiro, v. 6, no 11, p. 2439, 1993.

BARRETO, Afonso Henrique Lima. Triste fim de Policarpo Quaresma. São Paulo: Editora Moderna, 2011. $112 p$.

CARVALHO, José Murilo de. A formação das almas. São Paulo: Companhia das Letras, 1990.

COC - CASA DE OSWALDO CRUZ, 2019. Dicionário Histórico-Biográfico das Ciências da Saúde no Brasil (1832-1930). Disponível em: <http:// lepto.procc.fiocruz.br:8081/ dic/verbetes/escancimerj.htm\#historico>. Acesso em: 20 out. 2019.

COUTO, Miguel. No Brasil só há um problema nacional - a educação do povo. Rio de Janeiro: Typ do Jornal do Commércio. 1927, 1933.

COUTO, Miguel. Lições de Clínica Médica. Rio de Janeiro: Typografia Ao Luzeiro, 1916, v. 1, 350 p.

COUTO, Miguel. Lições de Clínica Médica. Rio de Janeiro: Typografia America, 1923, v.2, 378 p.

COUTO, Miguel. 0 Problema Nacional. Carta - falas, memórias, reflexões. Brasília, Senado Federal, no 5, 1992, p. 111-120.

CPDOC - CENTRO DE PESQUISAS E DOCUMENTAÇÃO DE HISTÓRIA. Biografias, Rio de Janeiro, Fundação Getúlio Vargas. Disponível em: http://www.cpdoc. fgv.br/nav historia/htm/ev biografias.htm. Acesso em: 20 out. 2019.

ENGEL, Magali Gouveia. Os intelectuais e a liga de defesa nacional: entre a eugenia e o sanitarismo (RJ, 1916-1933). Intellèctus, Rio de Janeiro, UERJ, Ano XI. no 1, p. 1-30, 2012. Disponivel em: https://www.e-publicacoes.uerj.br/index.php/intellectus/article/ view/27557 Acesso em: 15 set. 2019.

FERREIRA de JESUS, Wellington. A emenda Miguel Couto (1933) e a transformação na história do financiamento a educação no Brasil. Congresso Brasileiro de História da Educação (SBHE), V, 2008, Aracaju. Anais... Aracaju: UFES/UNIT, 2008. v. I. p. 1-14. 
FONSECA, Pedro Cezar Dutra. Gênese e precursores do desenvolvimentismo no Brasil. Pesquisa \& Debate, São Paulo, PUCSP, v. 15, no 2, p. 5-9, 2004. Disponivel em: https://revistas.pucsp.br/index.php/ rpe/article/view/11934 Acesso em: 15 set. 2019.

FOUCAULT, Michel. Os Intelectuais e o poder (Conversa entre Foucault e Deleuze) In: FOUCAULT, Michel. Microfísica do Poder. Rio de Janeiro: Ed. Graal, 2008. p. 69-78.

FREYRE, Gilberto. Casa-grande e Senzala. São Paulo: Global, 2006.

LAMARQUISMO. Wikipédia. Disponível em: https:// pt.wikipedia.org/wiki / Lamarquismo\#: :text=0\%20 lamarquismo\%20ou\%20lamarckismo\%20foi,causando\%20mudan\%C3\%A7as\%20no\%20seu\%20comportamento. Acesso em: 15 set. 2019.

LDN - LIGA DA DEFESA NACIONAL. Estatutos da Liga da Defesa Nacional. In: TEIXEIRA, Julio Cesar Benites; PINHEIRO, Marcos Elias; GIORGIS, Luiz Ernani. A História da LDN no Rio Grande do Sul. Porto Alegre: Edições da Liga de Defesa Nacional, 2016. p. 57-65.

MIKI, Bianca Sayuri. Os inassimiláveis: o antiniponismo na Assembleia Nacional Constituinte de 193334. 118 p, 2015. Dissertação (Mestrado em História) Programa de Pós-graduação em História, Pontificia Universidade Católica do Rio de Janeiro, 2015.

NAVARRO, Moacyr. Miguel Couto Vivo. Rio de Janeiro: A Noite, 1950.

NEIVA, Artur. \& PENNA, Belizário. Viagem científica pelo norte da Bahia, sudoeste de Pernambuco, sul do Piauí e de norte a sul de Goiás. Memórias do Instituto Oswaldo Cruz, v. 8, no 30, p. 74-224, 1912.

\section{O BRAZIL-MEDICO. Revista Semanal de Medicina e}

Cirurgia, Ano XV, p. 283-285, 1897. Disponivel em: https:// www.obrasraras.fiocruz.br/media.details. php?medialD=165 Acesso em: 20 out. 2019.
PINTO, Diana Couto. Miguel Couto. IN: FÁVERO, Maria de Lurdes de Albuquerque (Org). Dicionário de Educadores do Brasil. Rio de Janeiro, EdUFRJ, 2002. p. 825-832.

RIBAS, Maria Cristina Cardoso. Onze anos de correspondência: os Machados de Assis. Rio de Janeiro: Editora PUC Rio, 2008.

ROCHA, Heloisa Helena Pimenta. Imagens do analfabetismo: a educação na perspectiva do olhar médico no Brasil dos anos 20. 145 f., 1995. Dissertação (Mestrado em Educação) - Programa de Pósgraduação em Educação, Universidade Estadual de Campinas, 1995.

SCHWARCZ, Lilia Moritz. Previsões são sempre traiçoeiras: João Baptista de Lacerda e seu Brasil branco. História, Ciências, Saúde - Manguinhos, Rio de Janeiro, FIOCRUZ, v. 18, no 1, p. 225-242, jan.- mar. 2011. Disponivel em: https://www.scielo.br/pdf/ hcsm/v18n1/13.pdf. Acesso em: 15 set. 2019.

SCHWARCZ. Lilia Moritz. Lima Barreto: triste visionário. São Paulo: Companhia das Letras, 2017.

STEPAN, Nancy. Eugenia no Brasil, 1917-1940. In: HOCHMAN, Gilberto; ARMUS, Diego (Orgs). Cuidar, Controlar, Curar: ensaios históricos sobre saúde e doença na América Latina e Caribe. Rio de Janeiro: Ed. Fiocruz, 2004. p. 331-391.

TAKEUCHI, Marcia Yumi. A comunidade nipônica e a legitimação de estigmas: o japonês caricaturizado. Revista USP, São Paulo, USP, no 79, p. 173-182, set./ nov. 2008. Disponivel em: <http://www.revistas.usp. br/revusp/article/view/13703/15521> Acesso em: 15 set. 2019.

Recebido em: 28.02.2020 Revisado em: 23.04.2020 Aprovado em: 06.06.2020

José Mario d'Almeida é doutor em Biologia Parasitária pela Fundação Osvaldo Cruz (Fiocruz). Pós-doutor em História da Ciência pelo Programa de Pós-graduação em História das Ciências e das Técnicas e Epistemologia (HCTE) da Universidade Federal do Rio de Janeiro (UFRJ). Professor e pesquisador de Zoologia (Artrópodos) e Etologia (aposentado), ministrando disciplinas voluntariamente na Universidade Federal Fluminense (UFF). Pesquisador de História da Ciência (Biologia). E-mail: josemariodalmeida@id.uff.br

Claudia Alves d’Almeida é doutoranda em História da Ciência e Saúde na Fundação Osvaldo Cruz (Fiocruz). Diretora de escola do município do Rio de Janeiro. E-mail: claudiaalvesdalmeida@yahoo.com.br 